\title{
ABSORBING AEROSOL LEVELS ACROSS THE CENTRAL AND WESTERN HIMALAYAN REGION- A REMOTE SENSING APPROACH
}

\author{
Arka Ghosh $^{2}$, Manu Mehta ${ }^{1}$, Soubhik Biswas ${ }^{2}$, Mahak Gumber $^{3,}{ }^{*}$ and Meghna Mittal ${ }^{3}$ \\ ${ }^{1}$ Photogrammetry \& Remote Sensing Department, Indian Institute of Remote Sensing, Dehradun, India - manu@iirs.gov.in \\ 2 Jadavpur University, Kolkata, West Bengal, India \\ ${ }^{3}$ Banasthali Vidyapith, Rajasthan, India - (mehak0197, meghanmittal191997)@gmail.com \\ Commission V, SS: Atmosphere, Ocean, Weather and Climate
}

KEYWORDS: OMI, aerosol, Western Himalayas, Central Himalayas, linear trends

\begin{abstract}
:
Studies have shown that aerosol loading particularly due to the absorbing particles over Himalayan region might impact the snow properties and cover. Hence, a comprehensive study on the aerosol distribution over this large mountain ecosystem, particularly focussing on the absorbing particles requires utmost attention. The purpose of this study is to provide a statistical view of Aerosol Absorption Optical Depth (AAOD) levels derived from Ozone Monitoring Instrument (OMI) at $388 \mathrm{~nm}$ wavelength during the time period 2005-2017 over the Central and Western Himalayan region (25 - $40^{\circ} \mathrm{N}$ and $70-88^{\circ} \mathrm{E}$ ). To extract the aerosol data for the specified Himalayan region the NOAA Digital Elevation Model (DEM) has been utilized, followed by geo-processing of the daily AAOD data. Outcomes of such studies could provide useful inputs for capacity building activities using the remote sensing resources. We have presented the yearly, monthly and seasonal variability of absorbing aerosols levels over the study region.
\end{abstract}

\section{INTRODUCTION}

The Himalayan mountain region generates and maintains the climate over the entire northern part of the Indian subcontinent while influencing the atmosphere, causing hazardous weather events (Shekhar 2010). Recent studies have shown that the amount of snow cover over Himalayan region is depleting from the past few years (Kripalani 2003). The melting of snow cover has a significant impact on the environment of the Himalayan region as well as it effects the bio diversity and socio-economic life of the nearby area. Kulkarni et al., 2010 has shown that melting of snow cover might affect the water level of the rivers during summer season. Absorbing aerosols over Himalayan region might impact the snow properties and cover (Kaspari 2014; Xu 2009). In this paper the absorbing aerosol distribution trend on monthly, seasonal and annual basis have been determined using Aerosol Absorption Optical Depth (AAOD) daily data derived from Ozone Monitoring Instrument (OMI) for a period of 13 years $(2005$ - 2017) over the specified study region. The aerosol data have been considered over those Himalayan regions only, whose altitude is equal to or above than two thousand meters $(2000 \mathrm{~m})$ by deriving Digital Elevation Model (DEM) from the NOAA ETOPO1 Global Relief Model. The yearly, monthly and seasonal changeability of absorbing aerosols levels over the study region is discussed in this paper.

\section{STUDY AREA}

The study area which is chosen, covers the north western and central part of the Himalayan mountain range. It has been inferred in recent studies that the snow cover over western and central part of the Himalayan region is melting from the past few years which is affecting the Indian river basins (Kripalani 2003).

Coordinates of the study area are given below.

Latitude $=25.00^{\circ}$ to $40.00^{\circ} \mathrm{N}$;

Longitude $=70.00^{\circ}$ to $88.00^{\circ} \mathrm{E}$;

This study area is shown in Figure 1.

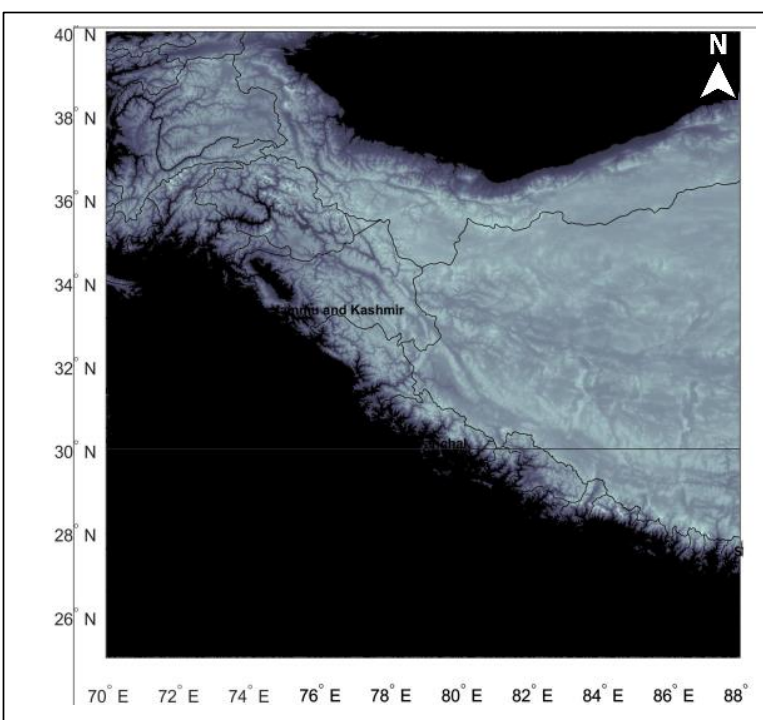

Figure 1: showing Central and Western Himalayan region, the elevation of our study area is equal and greater than 2000 meter. Latitude $=25.00^{\circ}$ to $40.00^{\circ} \mathrm{N} \&$ Longitude $=70.00^{\circ}$ to $88.00^{\circ} \mathrm{E}$;

\section{DATA USED}

3.1 OMI/Aura Level 3 Near UV Aerosol Absorption Optical Depth Gridded Data

The OMI Aura level 3 near UV daily global gridded aerosol data product is used in this paper over the study area to investigate the distribution of absorbing aerosols (Torres 2008).

\subsection{NOAA ETOPO1 Global Relief Model}

The ETOPO1 Global Relief Model provides "Ice Surface" (top of Antarctic and Greenland ice sheets) and "Bedrock" (base of the ice sheets) versions. Both versions of ETOPO1 were generated from diverse global and regional digital data sets (Amante 2009). Digital elevation model of the Himalayan region is deduced from this dataset. 


\section{METHODOLOGY}

The flow of methodology adopted for the both the remote sensing datasets (i.e. OMI Level 3 AAOD and NOAA ETOPO1) in producing the desired results has been show in Figure 2 with the help of a flowchart. The required AAOD datasets have been taken from the remote sensor OMI for the period of $2005-2017$ over the specified study area and the digital elevation dataset of the area is deduced using NOAA global ice data. The aerosol data is retrieved from the daily data set based on the coordinates of the chosen study area. Determination of the indices of those altitudes values greater than $2000 \mathrm{~m}$ have been done and the aerosol data have been extracted over those Himalayan regions only, whose altitude is equal to or above than two thousand meters $(2000 \mathrm{~m})$. The extracted data values formed a resampled AAOD data array. Using this data for the specified period of time the annual, monthly and seasonal variability of absorbing aerosol levels over the central and western Himalayan region have been calculated and results are generated.

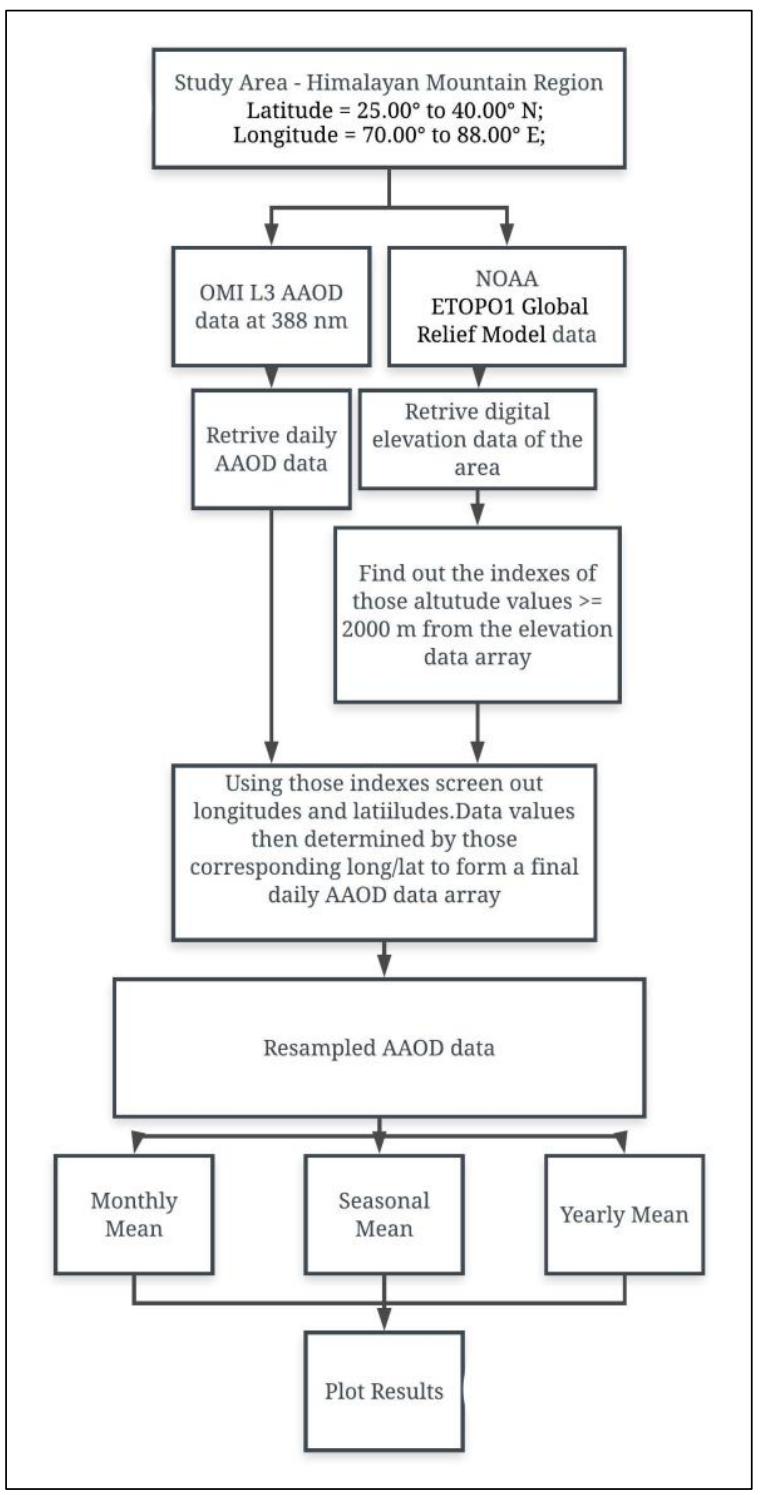

Figure 2. Methodology

\section{RESULTS AND DISCUSSION}

\subsection{Seasonal aerosol distribution over the study area}

Figure 3 shows the year wise seasonal aerosol distribution of DJF, MAM, JJA, SON. Seasonal variability of absorbing aerosol in the winter season December, January and February (DJF) is observed to be drastically increased after the year of 2012 while in the season March. April and May (MAM) and in June, July and August (JJA) the trend of aerosol is overall consistent throughout the year 2017. But in September, October and November (SON) the trend of aerosol distribution has increased steadily after the year 2011

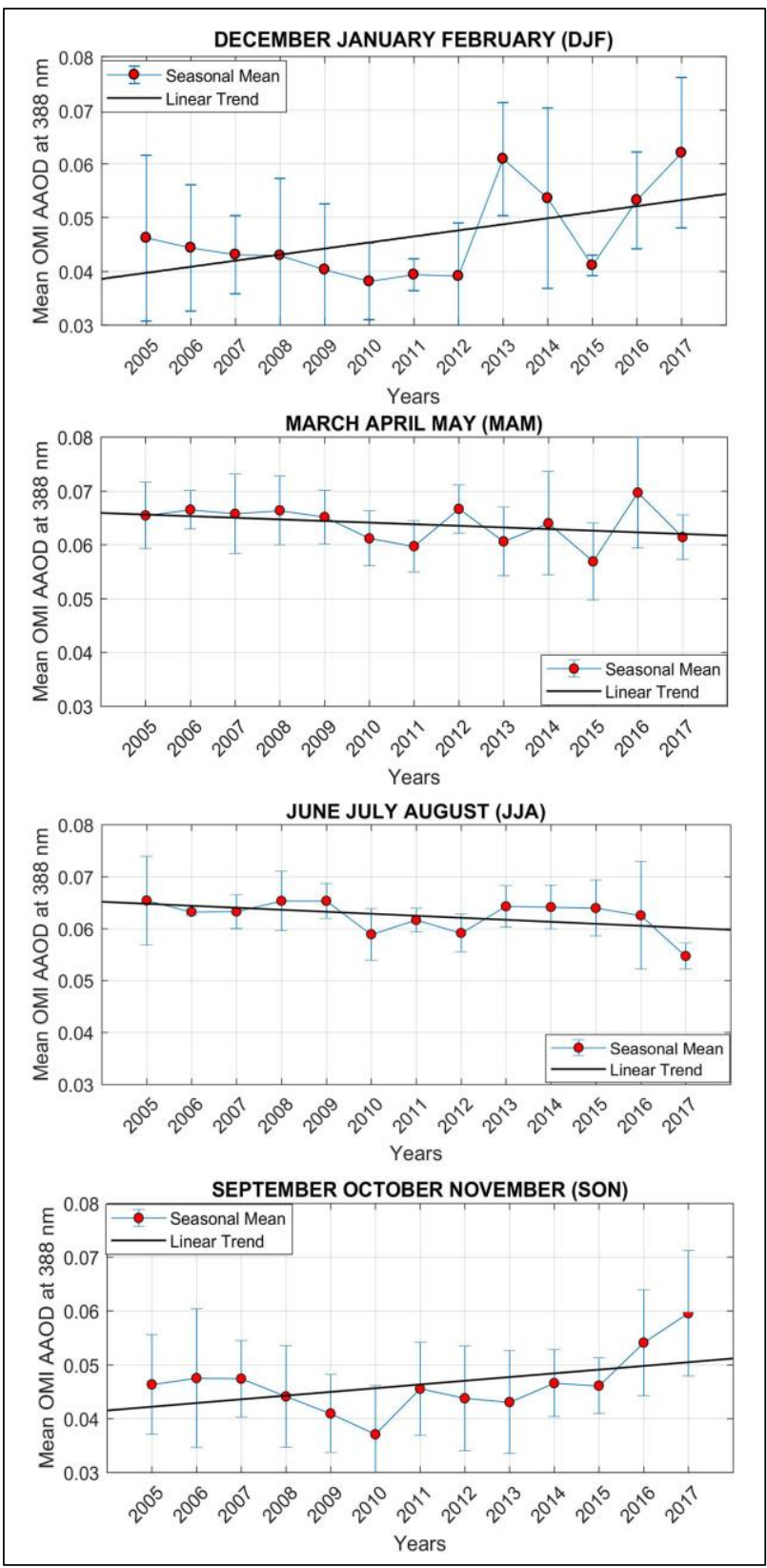

Figure 3. Seasonal mean of AAOD during DJF, MAM, JJA and SON with standard deviation. The linear trend lines for each season has also been displayed in the graph. 
In the Figure 4 the linear trend of monthly aerosol distribution in the months of November, December, January are observed to be increased heavily from the year 2012. It can be inferred that the absorbing aerosol distribution is getting increased during the months of winter over the study region from the past few years.

While in the month of February the aerosol trend is found to be decreasing year wise. Slight decrease in the aerosol distribution is found in the months of March, April, June and August. The aerosol variability is overall consistent in the months of May, July, September and October.

An inference can be drawn about the temporal variability of absorbing aerosol of the months after the winter season, are found to be either decreasing or remained consistent from the period of time 2005 to 2017 .

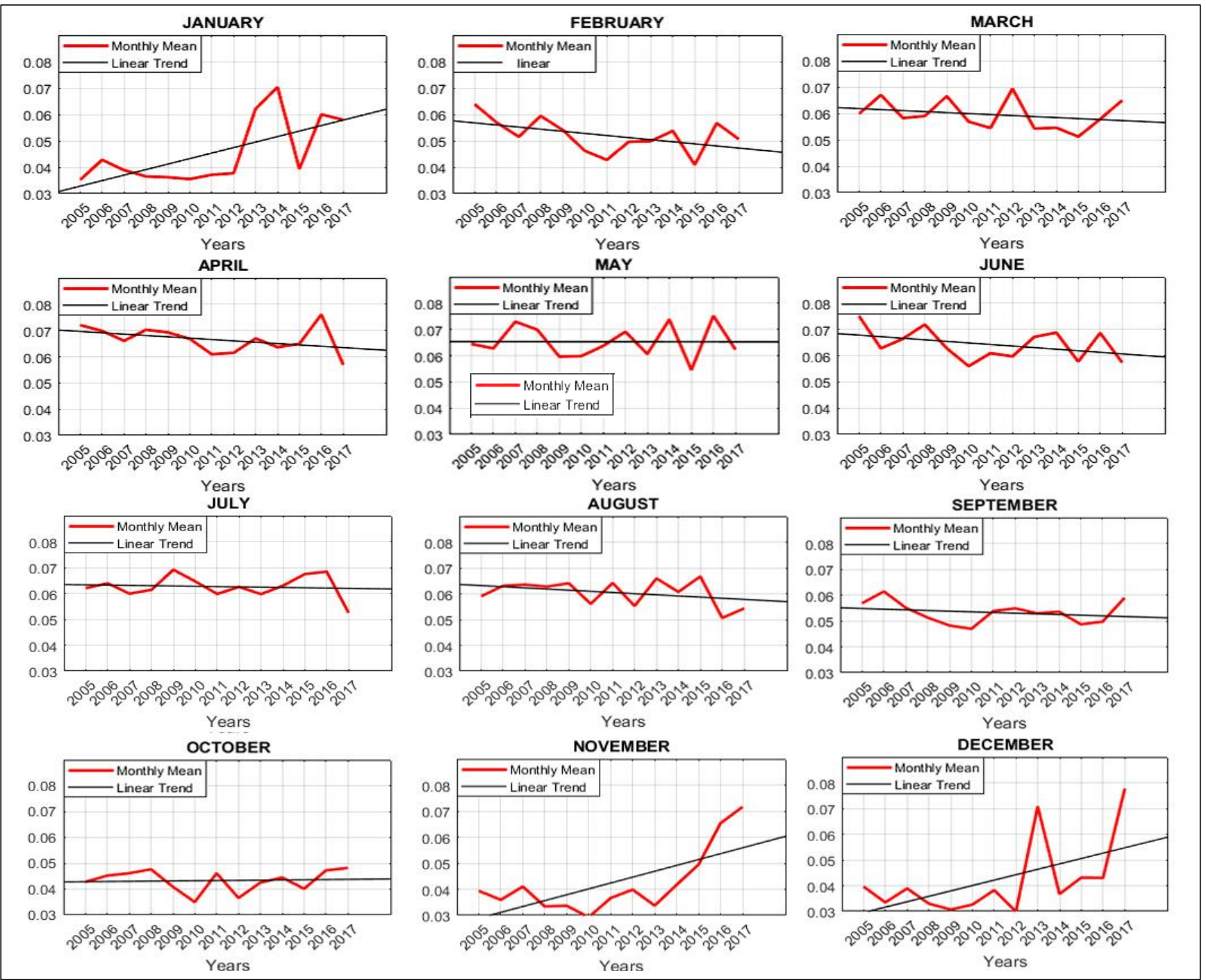

Figure 4. Year wise (2005 - 2017) monthly mean of each of twelve months along with standard deviation is observed. Linear trend lines for each month has also been plotted to show the chronological variability of absorbing aerosol over the study region.

\subsection{Annual aerosol distribution over the study area}

Annual trend of absorbing aerosol distribution over the study area is observed in the Figure 5. It is found that the aerosol distribution is increasing year wise from 2005 to 2017 . The linear trend has also slightly increased.

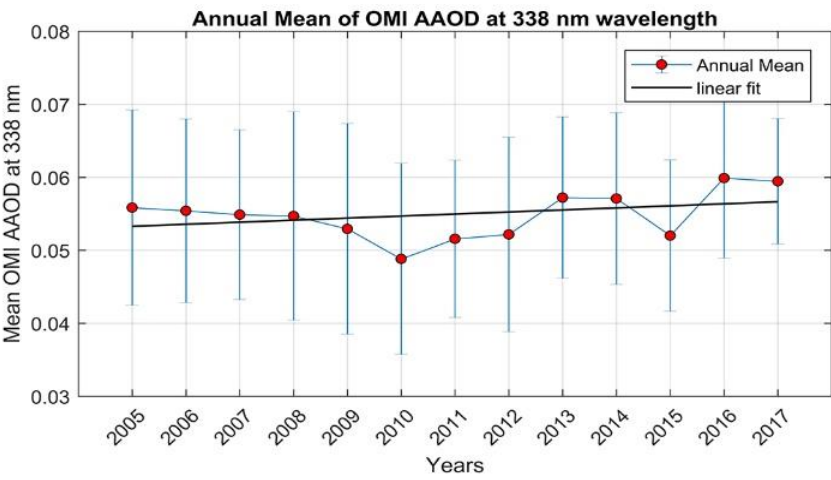

Figure 5. Annual mean of AAOD for the period of 2005 - 2017 along with standard deviation. Linear trend has also been displayed to observe the statistical variability of absorbing aerosol over the Himalayan region 


\section{CONCLUSION}

This study deals with the absorbing aerosol variability over the western and central Himalayan region during the time period of 2005 - 2017 . Following are the observations:

The distribution of absorbing aerosols is found to be increasing as the time passes, especially during the winter season the magnitude of aerosol distribution is much higher than other seasons and it might be affecting the snow cover of the western and central part of Himalayan region as snow covers are melting day by day which is serious environmental issue to the present global climate.

Further a comprehensive study of over the study area can be carried out using space borne lidar data.

Forward and backward air trajectory analysis can be performed to study the sources of the absorbing aerosols.

The aerosol distribution using ground measurement can also be done over this region and comparison of aerosol variability from different sensors can also be drawn in the future study.

\section{ACKNOWLEDGEMENT}

Our sincere thanks are due to the Editor for the valuable and insightful comments. Authors are extremely grateful to the potential reviewers for critically examining the work and providing their crucial suggestions which has helped to bring out the manuscript in the current form. We are most grateful to the entire OMI team for providing us access to OMI Level 3 Near UV Aerosol Absorption Optical Depth (AAOD) Gridded Data. Thanks to NOAA also for providing The ETOPO1 Global Relief Model to deduce the digital elevation model (DEM). Thanks, are also due to the Director, School of Oceanography, Jadavpur University, Kolkata and the Director of IIRS, Dehradun for their valuable support and encouragement.

\section{REFERENCES}

Amante, C., 2009. ETOPO1 1 Arc-Minute Global Relief Model: Procedures, Data Sources and Analysis, National Geophysical Data Center, NOAA, https://doi.org/10.7289/v5c8276m

Kaspari, S., Painter, T.H., Gysel, M., Skiles, S.M., Schwikowski, M., 2014. Seasonal and elevational variations of black carbon and dust in snow and ice in the Solu-Khumbu, Nepal and estimated radiative forcings. Atmospheric Chemistry and Physics 14, 8089-8103.

Kripalani, R.H., Kulkarni, A., Sabade, S.S., 2003. Western Himalayan snow cover and Indian monsoon rainfall: A re-examination with INSAT and NCEP/NCAR data. Theoretical and Applied Climatology 74, 1-18. https://doi.org/10.1007/s00704-002-0699-z

Kulkarni, A.V., Rathore, B.P., Singh, S.K., Ajai, 2010. Distribution of seasonal snow cover in central and western Himalaya. Annals of Glaciology 51, 123-128. https://doi.org/10.3189/172756410791386445 Shekhar, M.S., Chand, H., Kumar, S., Srinivasan, K., Ganju, A., 2010. Climate-change studies in the western Himalaya. Annals of Glaciology 51, 105-112. https://doi.org/10.3189/172756410791386508

Torres, O.O., 2008. OMI/Aura Near UV Aerosol Optical Depth and Single Scattering Albedo Daily L3 Global 1x1 deg Lat/Lon Grid. https://doi.org/10.5067/aura/omi/data3003

Xu, B., Cao, J., Hansen, J., Yao, T., Joswia, D.R., Wang, N., Wu, G., Wang, M., Zhao, H., Yang, W., Liu, X., He, J., 2009. Black soot and the survival of Tibetan glaciers. Proceedings of the National Academy of Sciences 106, 22114-22118. 